\title{
La experiencia de la autoconciencia en Hegel
}

\section{DANIEL PÉREZ CASTRO}

La distinción que toda conciencia establece entre lo que ella sabe y los objetos sobre los que versa tal saber es la base sobre la que Hegel va a desplegar progresivamente su Fenomenología del Espíritu. Con esta obra quiso brindarnos una comprensión completa de la Historia y de la conciencia individual, en la cual quede demostrado que el sujeto está detrás de la experiencia de las cosas, y que el hombre ha de transformar el mundo que le es extraño en un mundo que sea suyo. Este texto está enfocado al capítulo IV, dedicado a la Autoconciencia. En primer lugar, consideraremos la autoconciencia como una forma de vida que será capaz de superar su elemento meramente biológico y que es capaz de apoderarse del mundo, dominando aquello que desea. El resto del capítulo está dividido en dos partes. Por un lado, Hegel desarrolla la primera experiencia intersubjetiva de la conciencia que tiene la forma de una dialéctica entre el señor y el siervo. Por otro lado, atenderá a tres figuras de la autoconciencia, estoicismo, escepticismo y conciencia desgraciada, para determinar en qué grado disfrutan, o no, de libertad.

Los tres primeros capítulos de la Fenomenología están dedicados al objeto de la opinión sensible y desarrollan dialécticamente la evolución en su consideración como «esto». Se trata de una experiencia cognitiva en la que la conciencia busca la verdad en el objeto que tiene frente a ella. Su primera forma de saber será la certeza sensible, por ser la más inmediata respecto del objeto. Pero se trata de un saber pobre y abstracto en el que cada sujeto ocupa una posición distinta en el espacio, generando multitud de perspectivas que hacen imposible la unificación de la experiencia, ya sea en el ámbito individual o en el colectivo. La conciencia es luego puesta en el plano de la percepción. Aquí el objeto es considerado «cosa», es decir, unidad de múltiples propiedades. Comenzamos afirmando la cosa siendo lo que es sin más, en sí y para sí. Sin embargo, la cosa está enlazada con el resto de cosas de tal modo que sólo es, lo que es, mediante una relación negativa respecto a lo que no es ella. Finalmente el saber toma la forma del entendimiento, y es en este momento cuando la conciencia se percatará de que el objeto cobra entera objetividad al hacerse 
plenamente inteligible o racional. El entendimiento descubre que la conciencia se ve a sí misma al mirar en el fondo último de la cosa, pues la estructura del objeto y la del sujeto coinciden. Como resultado tenemos una transformación de la conciencia, que comenzó siendo conciencia objetiva al afirmar una objetividad absolutamente aislada o independiente de su propio acto, pero que se ha tornado conciencia subjetiva, cuando deja de considerar al objeto exterior, y se mira a sí misma.

\section{I. «AUTOCONCIENCIA» O SABER DE SÍ MISMO.}

Llegamos así al capítulo IV de la Fenomenología, donde coinciden saber y objeto, pues la conciencia se propone a ella misma como objeto de su saber. Ahora bien, la identificación entre ambos no será total, tendremos que seguir distinguiendo entre el polo objetivo y el polo subjetivo de la conciencia, aunque lo hagamos de otra manera. Con esta nueva figura del saber, que es el saber de sí mismo y al que llamamos autoconciencia, hemos entrado en el «reino nativo o autóctono de la verdad» (G.W.F. Hegel, 2006, p. 276). La autoconciencia no puede ser otra cosa que una reflexión a partir del mundo sensible y percibido, por eso el mundo no quedará aniquilado, pero sí referido y subordinado a ella, por ser las cosas del hombre y para el hombre que las somete y domina.

Hegel entiende la vida como proceso reproductivo, el movimiento de una unidad universal que se va fragmentando en géneros, especies e individuos. Y la autoconciencia es también una forma de vida. Pero el hombre, en cuanto sujeto, no sólo vive, sino que es la vida que se vive frente a sí misma y que mediante dicha experiencia es capaz de escapar a su carácter meramente biológico para poder abrazar aquello que en la Fenomenología se describirá posteriormente como espíritu. «La vida parece autotrascenderse a través de una torsión sobre sí misma que rompe la lógica del mundo orgánico para generar, más allá del viviente, un sujeto consciente de sí» (E. Álvarez, 2007, pp. 122-135).

Una vez que el hombre ha aprendido que su propia autoconciencia está detrás de la apariencia de las cosas tiene que demostrar que él es el dueño de su propio mundo. La autoconciencia se encuentra a sí misma en un estado de deseo (Begierde, cupiditas). Ansía los objetos que le rodean, así que se los apropia y los utiliza.

«La autoconciencia, que por de pronto es deseo, tendrá, pues, más bien que empezar haciendo experiencia de la autonomía de ese objeto» (G.W.F. Hegel, 2006, p. 279).

Sin embargo, durante este proceso llegará a sentir que los objetos no son el fin verdadero de su deseo, pues

«la autoconciencia sólo está o puede estar segura de sí mediante la supresión o separación de ese otro [o de eso otro] que se le presenta como vida autónoma» 
(G.W.F. Hegel, 2006, p. 283).

Sus necesidades sólo se pueden satisfacer a través de la asociación con otros individuos. Si «la autoconciencia sólo alcanza su satisfacción en una autoconciencia distinta, en otra autoconciencia» (G.W.F. Hegel, 2006, p. 285), como afirma Hegel, entonces el individuo sólo puede llegar a ser lo que es a través de otro individuo. La verdad de la autoconciencia no es el «Yo», sino el «Nosotros», el ego que es nosotros y el nosotros que es ego. Pero la primera experiencia de la intersubjetividad no será una relación armónica de cooperación entre individuos igualmente libres y animados por un interés común en pos de su mutua convivencia. Lejos de ello, nos encontraremos más bien con una «lucha a vida o muerte» entre individuos esencialmente desiguales. Tras la contienda, uno de ellos será convertido en siervo del otro, trabajará para él y lo reconocerá como su señor. El trabajo toma un papel determinante en este punto pues «Hegel muestra que los objetos del trabajo no son cosas muertas, sino encarnaciones vivas de la esencia del sujeto, de manera que al tratar con estos objetos el hombre está tratando, de hecho, con otros hombres» (H. Marcuse 2003, p. 117).

Veamos entonces la descripción que realiza Hegel de la dialéctica señorsiervo. Como decíamos, se trata de la primera y más pobre experiencia intersubjetiva, así que no garantizará la perfecta libertad e independencia de todos los miembros de la comunidad por igual. Tal situación no se alcanza hasta la plena realización del concepto hegeliano de espíritu.

\section{LA DIALÉCTICA SEÑOR-SIERVO}

Ramón Valls Plana explica que esta experiencia de la intersubjetividad está marcada por la manera en que la autoconciencia se relaciona con la naturaleza, y por ello cada autoconciencia realiza una «cosificación» del sujeto opuesto (R. Valls, 1971, pp. 111-137). Para llevar a buen término el ideal de la relación intersubjetiva será necesario un reconocimiento mutuo por parte de ambos sujetos, pues sólo podrá constituirse la unidad del espíritu mediante la afirmación recíproca de la libertad e independencia del prójimo. Sin embargo, aquí vamos a encontrarnos con que cada conciencia va a considerar que la otra es para él, pero no para sí misma, es decir, para cada una de las autoconciencias no hay más autoconciencia que ella misma. El yo se afirma como la autoconciencia que debe ser reconocida, por tal razón, la autoconciencia situada frente a mí es el yo que debe reconocerme, pues sólo así podré conocerme y realizarme como autoconciencia. Decimos entonces que cada una de las autoconciencias objetivará de tal modo a la otra que termina por cosificarla.

La autoconciencia ha surgido como negación de la naturaleza comportándose frente a ella como apetito. Se sabe por encima de la vida estrictamente biológica e independiente de la naturaleza y lo va a demostrar despreciando tanto 
la vida propia como la ajena. Con tal desprecio hacia la vida, la autoconciencia se refrenda como hombre, ante sí y ante los otros. Esta es la gran característica humana, la capacidad de arriesgar su propia vida y suponer una amenaza para la vida de los demás.

«La relación de ambas autoconciencias viene, pues, determinada de forma que ambas se acreditan cada una ante sí misma y la una frente a la otra mediante la lucha a vida o muerte» (G.W.F. Hegel, 2006, p.291).

Por ello, la persona que aún no ha arriesgado su vida es una autoconciencia en potencia cuya dignidad humana está por realizar. Su dignidad es exclusivamente subjetiva, puesto que no ha alcanzado su propia verdad al no haber vivenciado la experiencia real de su superioridad respecto de la mera biología.

Las conciencias van a entablar una lucha a muerte de la que surgirán los perfiles de los dos personajes de la dialéctica del señor y el siervo. Mientras que el señor se aferra con vigor a su conciencia humana y superior a la naturaleza, el siervo termina resignándose a la vida natural y será una cosa susceptible de ser propiedad de otro, tal como ocurriría con cualquier animal doméstico. Por la vía de tal lucha a muerte, el señor ha ganado en concreción, pasando de ser una conciencia inmediata y abstracta, a reflejarse en sí por mediación del siervo. A través de la conciencia servil y del mundo atado a esa conciencia servil, el señor puede relacionarse consigo mismo y ser para sí. Pero además, el siervo ejerce una segunda mediación en la que hace de filtro entre el señor y la cosa, porque es él quien tiene que enfrentarse de modo directo con la naturaleza y sufrir su resistencia. Por el contrario, el señor recibe la cosa de manos del siervo ya elaborada, domesticada o humanizada y no tiene otra cosa que hacer sino gozarla. Todo el trabajo servil tiene como finalidad que el señor viva como hombre saciado y dominador de la naturaleza. Así pues, el señor mantiene una relación de puro dominio respecto a la naturaleza y al siervo.

A pesar de todo, el señor no consigue ser perfectamente hombre. El ser humano consiste en relacionarse con el mundo sometiéndolo y experimentando su resistencia. Pero con la transferencia de esta segunda dimensión al siervo, él mismo se está deshumanizando. Además, el señor obtiene el reconocimiento por parte de una conciencia que no es libre, sino dependiente y cosificada, como es la del siervo. Así que, al haberse dividido lo humano entre señor y siervo, es imposible alcanzar todavía la comunidad espiritual igualitaria, y ninguno de los dos consigue ser plenamente hombre. Ser hombre significa tanto dominar como servir, es decir, alcanzar el dominio a través del servicio. El señor pretendía dominar sin prestar servidumbre, pero con ello tomó un atajo inadecuado. Por ello, quien saldrá mejor parado de esta dialéctica será precisamente el siervo.

Como resultado de dicha dialéctica tenemos una sorprendente inversión por la que el señor queda esclavizado y el siervo liberado. El señor necesita del 
siervo para ser hombre. De esta manera queda sometido contra su voluntad al esclavo y se convierte en un esclavo del esclavo. Consiguió su dominio sobre las cosas y el siervo gracias a que despreció la vida con valentía y arrojo. En cambio, el siervo se sometió porque sintió miedo. Pero tal miedo es una experiencia metafísica que va a poner al siervo en el camino correcto hacia su realización como hombre. En un primer momento el siervo se somete, y con esta actitud está erigiendo al señor como verdad objetiva. Todo su ser queda referido al señor y es así como se hace siervo. Pero la verdad del señor no le pertenece pues él no es de ninguna manera señor. Por medio del temor, la conciencia del siervo cobra una universalidad que se objetiva en su sometimiento al señor y que se realiza en el trabajo. Al trabajar el siervo está realizando su sometimiento y su temor, pero gracias a ello resulta ser un hombre concreto y real que vence a la cosa. Lo humano es vencer sobre el mundo, pero esto está fuera del alcance del señor a quien el mundo le llega ya vencido en virtud del esfuerzo que realiza el siervo. El objeto desaparece cuando es gozado o consumido, pero no al ser trabajado. Con el trabajo el objeto permanece, no idéntico sino transformado. Es en este sentido en el que podemos decir que el objeto natural ha sido vencido o superado, pero que al mismo tiempo se conserva. Con ello la cosa o el objeto natural se eleva a una categoría superior porque ha sido humanizado. Con su labor, el trabajador suprime la forma natural del objeto y consigue la objetivación de su propia subjetividad. En el objeto elaborado el siervo puede contemplarse a sí mismo y ver su propia singularidad.

Sin embargo, aunque el siervo alcance una satisfacción, que ya podemos considerar humana, por medio de su trabajo, no consigue aún el reconocimiento de la otra conciencia. Su satisfacción es solitaria y consecuentemente la dialéctica intersubjetiva no puede pararse aquí. Aún quedan pendientes el deseo de reconocimiento y el alcanzar una sociedad perfecta e igualitaria. Con la experiencia de la intersubjetividad que acabamos de narrar, no se ha conseguido todavía esa anhelada comunidad espiritual en la que el yo es un nosotros y el nosotros es un yo. Hemos iniciado el camino hacia la realización del concepto de espíritu, pero queda todavía un largo trecho por recorrer.

Este capítulo IV de la Fenomenología que Hegel ha dedicado a la autoconciencia continúa con una segunda parte, en la que el objeto de estudio es la libertad de esa autoconciencia, y analiza tres figuras de la autoconciencia: estoicismo, escepticismo y conciencia desventurada. La autoconciencia ganará una universalidad real superando su individualismo. Además, la escisión de la autoconciencia en autoconciencia de señor y autoconciencia de siervo se dará ahora en plano de una misma conciencia individual.

\section{ESTOICISMO, ESCEPTICISMO Y CONCIENCIA DESGRACIADA}

En su comentario literal de la Fenomenología del Espíritu, Kojève afirma 
que Hegel llama estoico al esclavo que se da cuenta de su situación (A. Kojève, 1971,pp.69-83). El estoico queda esclavizado a la naturaleza cuando sacia sus deseos, sin embargo, al pensar cobra su libertad. Es un esclavo que no aspira sin más a conservar su vida pues acepta que el amo lo castigue con la muerte en cualquier momento. Aceptando su propia muerte adquiere una libertad que será negativa, por oponerse al mundo refugiándose en sus pensamientos, y abstracta, ya que sólo es libre en su propio pensamiento. Tal pensamiento opuesto al mundo es vacío, trabaja pero no lucha. Así que la actitud del estoico es provisional y tornará a ser escéptico.

El escéptico destruye el ser mismo del mundo exterior, pero no lo hace activamente y en la realidad sino mentalmente. Se trata de una negación puramente teórica que entra en polémica con la ciencia. Puede pensar el Yo sin pensar el mundo exterior, y puede destruir al mundo sin destruirse él mismo, aunque sea en el ámbito del pensamiento. El escéptico no puede negar su lugar servil en el mundo del amo porque él tampoco actúa, no lucha contra el amo procurando que éste lo reconozca. Él es ya autoconciencia en tanto que hombre opuesto a la naturaleza y posee certeza de su libertad, sin embargo, la libertad no es una propiedad sino un acto. Por ser inviable, el escepticismo devendrá conciencia infeliz.

El hombre religioso es consciente de sí y de su oposición al mundo, lo que le hace aislarse del mundo. De ese aislamiento brota la desdicha de la que hará el contenido de su conciencia religiosa. Si se aísla es porque aún es Esclavo y vive en el hostil mundo del Amo. Pero ahora es reconocido y deviene esclavo de Dios. Ahora es igual que el Amo en el sentido de que ambos son igualmente esclavos de Dios. Sin embargo, no es realmente libre. El hombre religioso toma conciencia de las contradicciones del escéptico y se considera desdoblado en sí mismo aceptando sus dos «Yos». La relación del Amo y del Esclavo es proyectada en su interior cuando se sabe amo del mundo y esclavo de Dios. La reconciliación del hombre consigo mismo se producirá cuando éste se reconozca como espíritu, es decir, actor de la Historia y ciudadano del Estado. Entonces él será Dios. Sin embargo, el hombre religioso elige ser, entre sus dos Yos, el Yo trascendente. Quiere trascender el Mundo sin transformarlo por la acción negadora de la lucha y del trabajo. No actúa como individuo social, sino como individuo aislado. No quiere hacer algo en este mundo ni para los demás. Sus actos son para él mismo ya que lo único que ansía es el reconocimiento de Dios.

Ese hombre religioso, que no es capaz de llegar a la unidad consigo mismo, no alcanzará jamás la satisfacción que es el fin supremo, y la justificación última de la existencia humana. Para ello deberá abandonar la idea del más allá y reconocer que su verdadera y única realidad es su existencia activa en el Mundo, donde nace, vive y muere. Esto supondrá dejar de ser el Hombre de 
la autoconciencia para entrar en el Hombre de la Razón. Pero para hablar de ello, tendríamos que seguir avanzando en la lectura y comentario de la Fenomenología del Espíritu.

\section{REFERENCIAS:}

ÁLVAREZ,E., 2007: «La génesis de la subjetividad: vida y autoconciencia en la Fenomenología del Espíritu de Hegel» en Eikasia. Revista de Filosofía, año III, $\mathrm{n}^{\mathrm{o}} 15$.

HEGEL, G.W.F., 2006: Phänomenologie des Geistes, (trad. Manuel Jimenez Redondo, Valencia: Pre-textos).

KOJÈVE, A., 1971: Introduction à la lecture de Hegel : leçons sur "La Phénoménologie de l'Esprit” (trad. J. José Sebreli, Buenos Aires: La pléyade).

MARCUSE, H., 2003: Reason and Revolution: Hegel and the Rise of Social Theory (Trad. J. Fombona, Madrid: Alianza editorial).

VALLS, R., 1971: Del yo al nosotros: lectura de la Fenomenología del Espíritu de Hegel, Barcelona: Editorial Estela. 
